\title{
Outpatient ESD for challenging colorectal lesions: Is it feasible and safe for western countries?
}

\section{(ㄷ)(1) $\odot$}

Authors

Silvia Pecere ${ }^{1,2}$, Federico Barbaro', ${ }^{1,2}$ Lucio Petruzziello ${ }^{1,2}$, Luigi Giovanni Papparella1,2, Marco Napoli ${ }^{1,2}$, Ivo Boskoski $^{1,2}$, Guido Costamagna1,2

Institutions

1 Fondazione Policlinico Universitario A. Gemelli IRCCS, Digestive Endoscopy Unit, Rome, Italy

2 Università Cattolica del Sacro Cuore, Centre for Endoscopic Research Therapeutics and Training CERTT, Rome, Italy

submitted 6.7.2020

accepted after revision $\quad 2.11 .2020$

\section{Bibliography}

Endoscopy International Open 2021; 09: E438-E442

DOI 10.1055/a-1333-1736

ISSN 2364-3722

(C) 2021. The Author(s).

This is an open access article published by Thieme under the terms of the Creative Commons Attribution-NonDerivative-NonCommercial License, permitting copying and reproduction so long as the original work is given appropriate credit. Contents may not be used for commecial purposes, or adapted, remixed, transformed or built upon. (https://creativecommons.org/licenses/by-nc-nd/4.0/)

Georg Thieme Verlag KG, Rüdigerstraße 14,

70469 Stuttgart, Germany

Corresponding author

Dr. Silvia Pecere, Endoscopy Unit, Division of Medicine, Gastroenterology and Endoscopy, Fondazione Policlinico

A. Gemelli, Largo Gemelli 8, Rome, 00168, Italy

Fax: +06-35510330

silvia.pecere@gmail.com

\section{ABSTRACT}

Background and study aims The need for hospital beds during the COVID-19 pandemic almost overwhelmed the health care systems all over the world. Therefore, elective non-life-saving procedures were postponed. We decided to perform all colorectal endoscopic mucosal dissections (ESDs) for challenging lesions as outpatient procedures, organizing an ad hoc path to management of any delayed post-procedural complications. The aim of the present study was to retrospectively evaluate the feasibility and safety of outpatient ESD for colorectal tumors.

Patients and methods From March 2020 to May 2020, outpatient colorectal ESDs were performed for 15 challenging lesions. We retrospectively investigated feasibility and safety of the procedures, rates of en bloc resection, and complications rates.

Results The mean age of the patients was 66.5 years and $40 \%$ of the them were on antiplatelet/anticoagulation therapy. Median size of removed lesions was $45 \mathrm{~mm}$ (range $32-77$ ) and $38 \mathrm{~mm}$ (range 24 to 55 ) Five patients (33\%) had rectal tumors extending to the dentate line and four (26.6\%) were recurrences on a scar of previous endoscopic or surgical local resections. All complications, such as bleeding or visible microperforation, were managed endoscopically and no delayed perforations occurred. One patient had fever $\left(37.5^{\circ} \mathrm{C}\right)$, while three patients complained of anal pain after ESD for a rectal tumor that extended to the dentate line (RTDL); all patients were managed conservatively.

Conclusion Outpatient colorectal ESD is feasible and safe for challenging lesions. It reduces costs of hospitalization but direct access to the endoscopy service to manage potential post-ESD complications should always be guaranteed.

\section{Introduction}

Colorectal endoscopic submucosal dissection (ESD) is a challenging procedure, potentially associated with intraprocedure or post-procedural complications such as bleeding, perforation or coagulation syndrome (CS). It is usually recommended dur- ing hospitalization [1-3], especially for patients with risk factors or those who require anticoagulation therapy [4]. The COVID-19 pandemic stressed health care systems all over the world with an inflow of COVID-19 patients and all elective nonlife-saving procedures had to be postponed [5-6]. The same happened in our endoscopy unit, and only urgent and oncolo- 
gic procedures were allowed, because beds for COVID-19-positive patients who required hospital treatment were urgently needed and almost all departments were transformed into COVID-19 units. However, many patients were on the waiting list for ESD. As we were unaware when we would be able to resume regular patient admissions to the wards, we decided to perform all colorectal ESDs for superficial neoplastic lesions suspected or at high risk for cancer evolution as outpatient procedures, including those technically demanding, larger than $5 \mathrm{~cm}$, and usually requiring hospitalization. Upper gastrointestinal ESD, usually performed under general anesthesia and endotracheal intubation, was excluded from outpatient management.

To handle possible adverse events (Aes), an ad hoc path was created to manage any delayed post-procedural complications and avoid access to the emergency department and higher infection risks with SARS-CoV-2. Data on all colorectal ESDs performed as outpatient procedures from March 7, 2020 until May 20, 2020 were collected and analyzed. The feasibility and safety of ESD as an outpatient procedure and potential risk factors related to outcomes were evaluated.

\section{Methods and procedures}

This was a retrospective analysis of a prospective medical database of consecutive colorectal ESD outpatient procedures performed for challenging lesions ( $>40 \mathrm{~mm}$ in diameter, sessile and lateral spreading tumors, and presence of submucosal fibrosis) [7]. Indications for ESD were large, non-pedunculated, colorectal lesions classified according to the Paris classification [8]. Contraindications for the procedure included advanced or ulcerated lesions, platelet count $<50,000$, and inadequate bowel preparation. Demographic and clinical data including patient age, sex, pathological diagnosis, lesion size, location, procedure outcomes, and AEs were collected for all patients ( $\triangleright$ Table 1). All data were collected in an Excel database. All patients followed the preoperative protocol for COVID-19 in our endoscopy unit according to European Society of Gastrointestinal Endoscopy guideline [9]. Risk stratification of patients for possible COVID-19 infection was performed 1 day prior to gastrointestinal endoscopy by phone and then again on the day of endoscopy by questioning for symptoms and contacts. Moreover, temperature measurement and immune rapid tests for virus infection were available for each patient as triage tests before entering the endoscopy room.

Primary study outcomes were incidence of delayed major complications (e.g. bleeding, perforation) and secondary outcomes were the evaluation of procedure time, intraprocedural complications, and mucosal defect closure rates. All procedures were performed by three experts (LP, FB, SP). All patients were informed about the endoscopic technique and possible complications and signed an informed consent. Procedures were performed under conscious sedation with intravenous midazolam and pethidine or fentanyl. Carbon dioxide insufflation was used. All lesions were resected using a standard technique [10]. A distal attachment under the exfoliated mucosa ensured a good counter traction to the submucosal layer and visualization of the operative field to facilitate evaluation of the submucosal (SM) layer. For all procedures, gastroscopes with a water-jet system (2.8-mm working channel diameter, Olympus, Tokyo, Japan) or operative gastroscopes (3.7-mm working channel diameter, Olympus, Tokyo, Japan) with Dualknife (1.5 mm, KD-650Q; Olympus, Tokyo, Japan) were used. The electrosurgical units were VIO 300D (ERBE Elektromedizin GmbH, Tubingen, Germany), with Endocut I and Swift Coagulation 3/40 or Dry Cut and Swift Coagulation 3/30 as parameters of eletrocautery settings.

All patients had to stay close to the hospital for 48 hours after the procedure to ensure faster management of any delayed complications. They were managed according to an "ad hoc path," which provided the possibility of calling an emergency number, which was answered by endoscopist on call. If necessary, direct access to the endoscopy unit was guaranteed and colonoscopy was performed in the Emergency Room.

\section{Results}

During the COVID-19 pandemic, 15 endoscopic colorectal ESDs were performed as outpatient procedures. The mean age of the patients was 66.5 years and $40 \%$ of them were on antiplatelet/ anticoagulation therapy managed according to guidelines. Comorbidities are shown in $>$ Table 1 . The median size of the removed lesions was was $45 \mathrm{~mm}$ (range $32-77$ ) $\mathrm{mm}$ and $38 \mathrm{~mm}$ (range 24-55) Five (33\%) of these were rectal tumors extending to the dentate line (RTDL) and four (26.6\%) were recurrences on a scar from previous endoscopic or surgical local resection ( $\downarrow$ Table 2 ). All lesions (100\%) were removed en-bloc ( Fig. 1 and $>$ Fig.2) Bleeding was endoscopically controlled with a closed tip Dual knife and monopolar forceps (Coagrasper). In three cases (two cancers and one adenoma), prevention of delayed bleeding was managed by clipping visible vessels on the ulcer site. Immediate and visible microperforation, defined as focal injury of muscularis propria (MP) [11], was seen in three patients (20\%) and was managed with clipping ( Fig.3). Monitoring of vital signs and clinical symptoms was done for 3 hours after each procedure. All patients were discharged in good clinical condition. Delayed bleeding occurred in one patient who did not need hospitalization; another patient had fever $\left(37.5^{\circ} \mathrm{C}\right)$ while three patients complained of

\begin{tabular}{|l|l|}
\hline Table 1 Patient characteristics. & \\
\hline Mean age & $66.5 \mathrm{y}$ \\
\hline Sex & $11 \mathrm{M} / 4 \mathrm{~F}$ \\
\hline Anticoagulants & 1 \\
\hline Antiplatelet drugs & 5 \\
\hline Hypertension & 9 \\
\hline Diabetes & 1 \\
\hline Respiratory disease & 3 \\
\hline RCU & 1 \\
\hline Previous Treatment - endoscopic/surgical & $3 / 1$ \\
\hline
\end{tabular}


- Table2 Technical features of challenging colorectal ESD.

\begin{tabular}{|c|c|c|c|c|c|c|c|c|}
\hline $\begin{array}{l}\text { Mor- } \\
\text { phology }\end{array}$ & $\begin{array}{l}\text { Size } \\
(\mathrm{mm})\end{array}$ & Site & $\begin{array}{l}\text { Type of sm } \\
\text { injection }\end{array}$ & $\begin{array}{l}\text { Fibrosis } \\
\text { (score) }^{1}\end{array}$ & $\begin{array}{l}\text { Intraproce- } \\
\text { dural bleed- } \\
\text { ing/man- } \\
\text { agement }\end{array}$ & $\begin{array}{l}\text { Intraproce- } \\
\text { dural perfora- } \\
\text { tion/manage- } \\
\text { ment }\end{array}$ & $\begin{array}{l}\text { Proce- } \\
\text { dure } \\
\text { Time } \\
\text { (min) }\end{array}$ & Histology \\
\hline LST- GM & $45 * 40$ & RT & $\begin{array}{l}\text { glycerol + IC+ } \\
\text { adrenaline }\end{array}$ & $\mathrm{F} 1$ & $\begin{array}{l}\text { Dual Knife + } \\
\text { Coagrasper }\end{array}$ & no & 180 & T LGD adenoma \\
\hline LST-GM & $40 * 35$ & RT & $\begin{array}{l}\text { glycerol + IC + } \\
\text { adrenaline + } \\
\text { orise gel }\end{array}$ & $\mathrm{F} 1$ & $\begin{array}{l}\text { Dual Knife + } \\
\text { coagrasper + } \\
\text { clipping }\end{array}$ & no & 65 & T HGD adenoma \\
\hline $0-\| 1 a+$ Is s & $75 * 55$ & RTDL & $\begin{array}{l}\text { glycerol + IC + } \\
\text { adrenaline + } \\
\text { orise Gel }\end{array}$ & $\mathrm{F} 2$ & $\begin{array}{l}\text { Dual Knife + } \\
\text { Coagrasper + } \\
\text { clipping }\end{array}$ & no & 152 & $\begin{array}{l}\text { Adenocarcinoma in } \\
\text { situ (Tis) }\end{array}$ \\
\hline Scar lesion & $35 * 30$ & RT & glycerol+IC & F3 & $\begin{array}{l}\text { Hybrid Knife + } \\
\text { Coagrasper }\end{array}$ & no & 75 & TV LGD adenoma \\
\hline LST GM & $95 * 85$ & RT & glycerol+IC & $\mathrm{F} 2$ & $\begin{array}{l}\text { Dual Knife + } \\
\text { Coagrasper }\end{array}$ & yes - clipping & 275 & Adenocarcinoma T1 \\
\hline NG-LST & $30 * 18$ & SF & $\begin{array}{l}\text { orise gel + } \\
\text { glycerol + IC }\end{array}$ & $\mathrm{F} 3$ & $\begin{array}{l}\text { Dual Knife + } \\
\text { Coagrasper }\end{array}$ & yes - clipping & 185 & Adenocarcinoma T1 \\
\hline Is + IIa & $80 * 75$ & SC & glycerol+IC & $\mathrm{F} 1$ & $\begin{array}{l}\text { Dual Knife + } \\
\text { Coagrasper } \\
\text { + clipping }\end{array}$ & no & 180 & Adenocarcinoma T1 \\
\hline LST- GM & $85 * 55$ & RT & glycerol+IC & $\mathrm{F} 1$ & $\begin{array}{l}\text { Dual Knife + } \\
\text { Coagrasper }\end{array}$ & no & 170 & Adenocarcinoma T1 \\
\hline NG-LST & $45^{*} 38$ & RTDL & $\begin{array}{l}\text { voluven + IC + } \\
\text { lidocain }\end{array}$ & $\mathrm{F} 1$ & $\begin{array}{l}\text { Dual Knife + } \\
\text { Coagrasper }\end{array}$ & no & 70 & Adenocarcinoma T1 \\
\hline Is + IIa & $65 * 55$ & $\begin{array}{l}\text { RS junc- } \\
\text { tion }\end{array}$ & voluven + IC & $\mathrm{F} 1$ & $\begin{array}{l}\text { Dual Knife + } \\
\text { Coagrasper }\end{array}$ & no & 120 & T LGD adenoma \\
\hline GM- LST & $90 * 85$ & RTDL & glycerol+IC & $\mathrm{F} 1$ & $\begin{array}{l}\text { Dual Knife + } \\
\text { Coagrasper }\end{array}$ & no & 170 & TV LGD adenoma \\
\hline$|s+I| a$ & $25 * 15$ & RTDL & glycerol+IC & $\mathrm{F} 2$ & $\begin{array}{l}\text { Dual Knife + } \\
\text { Coagrasper }\end{array}$ & no & 134 & ASIN \\
\hline Scar lesion & $40 * 38$ & RT & $\begin{array}{l}\text { glycerol + IC+ } \\
\text { adrenaline }\end{array}$ & $\mathrm{F} 3$ & $\begin{array}{l}\text { Dual Knife + } \\
\text { Coagrasper }\end{array}$ & yes-clipping & 250 & TV HGD adenoma \\
\hline Scar lesion & $20 * 15$ & RTDL & $\begin{array}{l}\text { glycerol + IC+ } \\
\text { xylocaina }\end{array}$ & $\mathrm{F} 3$ & $\begin{array}{l}\text { Dual Knife + } \\
\text { Coagrasper }\end{array}$ & no & 210 & T LGD adenoma \\
\hline Scarlesion & $25^{*} 13$ & RTDL & glycerol+IC & F3 & $\begin{array}{l}\text { Dual Knife + } \\
\text { Coagrasper }\end{array}$ & no & 138 & T HGD adenoma \\
\hline \multicolumn{9}{|c|}{$\begin{array}{l}\text { Morphology: According Paris classification [8] } \\
\text { ESD, endoscopic submucosal dissection; RTDL, rectal tumor extending to the dentate line; SF, splenic flexure; SC, sigmoid-colon; RS, rectosigmoid; sm, submucos } \\
\text { injection; IC, Indigo Carmine; T, tubular histology; TV, tubular-villous; LGD, low-grade dysplasia; HGD, high-grade dysplasia; ASIN, anal squamous intraepithelial } \\
\text { neoplasia. } \\
{ }^{1} \text { Fukunaga S, Nagami Y, Shiba M et al. Impact of preoperative biopsy sampling on severe submucosal fibrosis on endoscopic submucosal dissection for colorectal } \\
\text { laterally spreading tumors: a propensity score analysis. Gastrointest Endosc } 2019 ; 89: 470-478 \text { doi: } 10.1016 / j . g i e .2018 .08 .051\end{array}$} \\
\hline
\end{tabular}

anal pain after ESD for RTDL; all patients were managed conservatively.

\section{Discussion}

The SARS-CoV-2 pandemic has stricken national health systems all around the globe, requiring a reorganization of endoscopy units. In the pre-COVID-19 period, all technically challenging
ESDs were routinely performed in the hospital. To ensure endoscopic resection of colorectal superficial neoplastic lesions and to reduce the waiting lists as much as possible, 15 colorectal ESDs were performed on outpatients, because most of the hospitalization wards from March 7, 2020 until the end of June were entirely occupied by COVID-19 patients. Considering that the risk of bleeding associated with colorectal ESD ranges from $0 \%$ to $11.9 \%[12,13]$, which is higher in Western than in Asian 

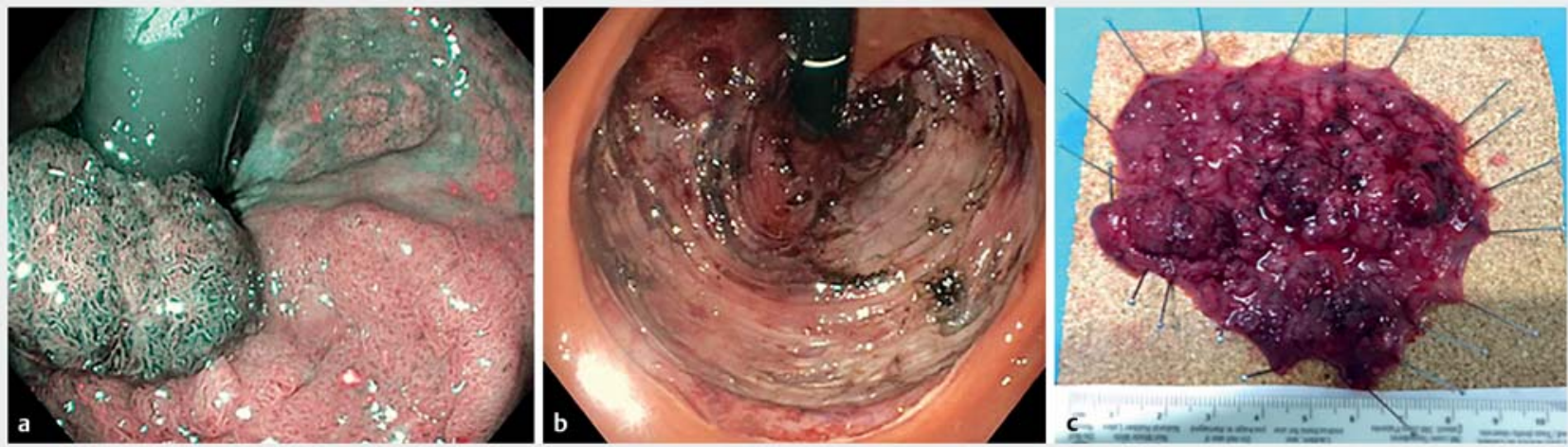

- Fig. 1 a and b Rectal tumor (GM-LST) extending to the dentate line (RTDL) before and after ESD. c Specimen assessment for histologic evaluation.
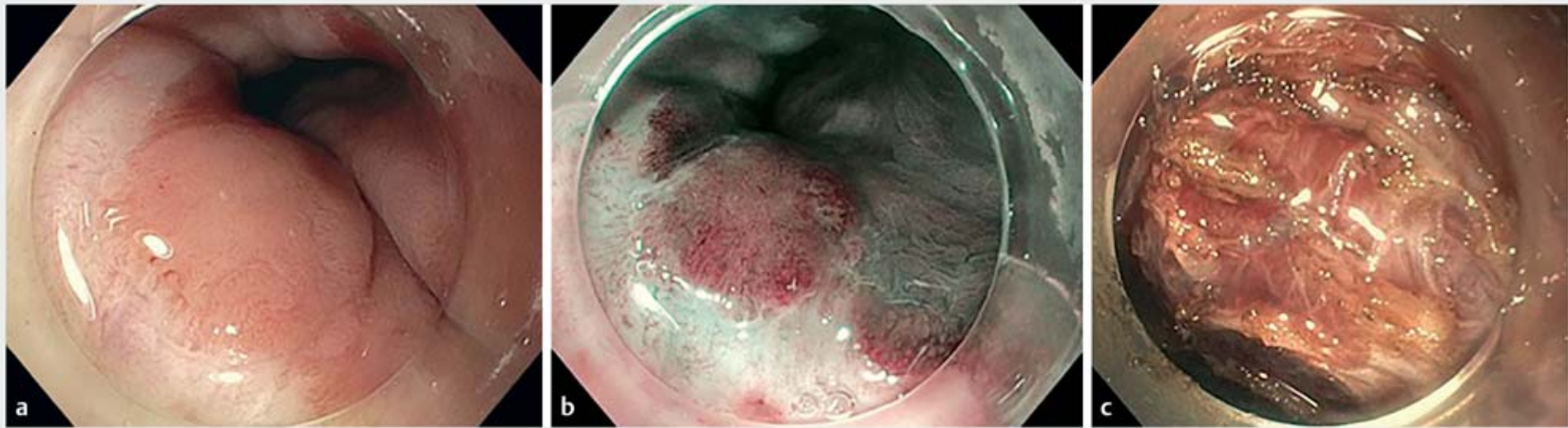

- Fig. 2 Scar lesion extending to the dentate line (RTDL) in ulcerative colitis visualized with a white and $\mathbf{b}$ narrow banding imaging (NBI). c Submucosal dissection with evidence of severe fibrosis (F3).
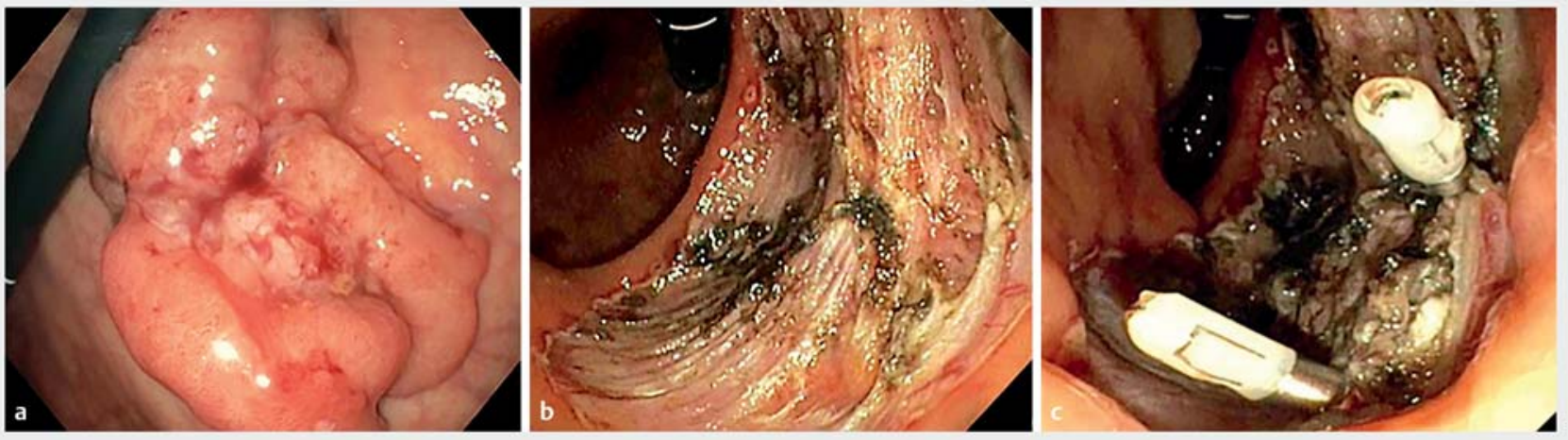

Fig. 3 a Retroflex vision for diagnostic evaluation of b rectal tumor resected with ESD. c Suturing with endoclips for intraprocedural microperforation.

countries [14], our experience with colorectal ESD has been encouraging. Analyzing our data case-by-case, intraprocedural complications such as bleeding seemed to be unrelated to the size, site, and submucosal injection type, but the only impact was on the duration of the procedure. Moreover, tumor size, high grade of submucosal fibrosis, and colonic location are known risk factors for perforation $[11,15]$. In our experience, the majority of ESDs showed these characteristics, but no delayed perforations occurred even if routine suturing and closure of mucosal defects were not performed, and long-lasting submucosal injection agents such as hyaluronic acid were not used. Restrictions linked to the COVID-19 pandemic forced us to perform difficult and challenging procedures on an outpatient service. However, the limited number of cases prevents us 
from drawing definitive conclusions or recommendations, but encourages us to argue that outpatient colorectal ESD is feasible and safe. Although in our series no correlation between post-procedural complications and anticoagulant use was demonstrated, certainly concomitant medications, age or any comorbidities of the patients must be taken into consideration before planning outpatient colorectal ESD, mainly to ensure direct access to the endoscopy service to quickly manage any potential post-ESD complications. Finally, endoscopist experience is essential for two reasons: the success of the procedure and the management of complications. In fact, an expert endoscopist (> 80 colorectal procedures performed with en bloc rate $>90 \%$ ) can guarantee proper technical ESD execution, which enables not only the success of the procedure itself but also optimal management of all possible intra-procedural complications without sequelae that would require patient hospitalization.

\section{Conclusion}

Performing outpatient ESD in complicated cases may reduce the general costs of hospitalization, but the data from this study need to be confirmed in a larger prospective study.

Competing interests

The authors declare that they have no conflict of interest.

\section{References}

[1] Saito Y, Uraoka T, Yamaguchi Y et al. A prospective, multicenter study of colorectal endoscopic submucosal dissections (with video). Gastrointest Endosc 2010; 72: 1217-1225

[2] Yoshida N, Wakabayashi N, Kanemasa K et al. Endoscopic submucosal dissection for colorectal tumors: technical difficulties and rate of perforation. Endoscopy 2009; 41: 758-761
[3] Otake Y, Saito Y, Sakamoto T et al. New closure technique for large mucosal defects after endoscopic submucosal dissection of colorectal tumors (with video). Gastrointest Endosc 2012; 75: 663-667

[4] Liaquat H, Rohn E, Rex DK. Prophylactic clip closure reduced the risk of delayed postpolypectomy hemorrhage: experience in 277 clipped large sessile or flat colorectal lesions and 247 control lesions. Gastrointest Endosc 2013; 77: 401-407

[5] Magro F, Abreu C, Rahier JF. The daily impact of COVID-19 in gastroenterology. United European Gastroenterol J 2020: doi:10.1177| 2050640620920157

[6] Sinonquel P, Roelandt P, Demedts I et al. COVID-19 and gastrointestinal endoscopy: what should be taken into account? Dig Endosc 26.04 2020: doi:10.1111/den.13706

[7] Iacopini F, Saito Y, Bella A et al. Colorectal endoscopic submucosal dissection: predictors and neoplasm-related gradients of difficulty. Endosc Int Open 2017; 5: E839-E846

[8] Participants in the Paris Workshop. The Paris endoscopic classification of superficial neoplastic lesions: esophagus, stomach, and colon: November 30 to December 1, 2002. Gastrointest Endosc 2003; 58: S3S43

[9] Gralnek IM, Hassan C, Beilenhoff U et al. ESGE and ESGENA Position Statement on gastrointestinal endoscopy and the COVID-19 pandemic. Endoscopy 2020; 52: 483-490

[10] Toshihiro N, Naohisa Y. Endoscopic mucosal resection and endoscopic submucosal dissection. Curr Opin Gastroenterol 2017; 33: 315-319

[11] Burgess NG, Bassan MS, McLeod D et al. Deep mural injury and perforation after colonic endoscopic mucosal resection: a new classification and analysis of risk factors. Gut 2017; 66: 1779-1789

[12] Tanaka S, Kashida H, Saito Y et al. JGES guidelines for colorectal endoscopic submucosal dissection/endoscopic mucosal resection. Dig Endosc 2015; 27: 417-434

[13] Yamamoto K, Michida T, Nishida T et al. Colorectal endoscopic submucosal dissection: recent technical advances for safe and successful procedures. World J Gastrointest Endosc 2015; 7: 1114-1128

[14] Fuccio L, Hassan C, Ponchon T et al. Clinical outcomes after endoscopic submucosal dissection for colorectal neoplasia: a systematic review and meta-analysis. Gastrointest Endosc 2017; 86: 74-86.e17

[15] Hong SN, Byeon JS, Lee BI et al. Prediction model and risk score for perforation in patients undergoing colorectal endoscopic submucosal dissection. Gastrointest Endosc 2016; 84: 98-108 